\title{
A Study on Diagnostic Importance of Fiber Optic Laryngoscopy (FOL) in Patients with Upper Airway Disorders
}

\author{
S MAHBUB $^{\mathrm{a}}$, AZAAL-AMIN ${ }^{\mathrm{b}}$, SS BISWAS ${ }^{\mathrm{c}}$, MS JAMAL ${ }^{\mathrm{d}}$
}

Summery:

Background: Upper airway symptoms are quite common. Many of these symptoms underlie serious upper airway pathologies which should be diagnosed at an early stage so that optimum treatment can be given. Often it seems to be difficult to diagnose upper air way pathology by conventional indirect laryngoscopy (I/L), especially when the lesion is at an early stage. In this situation fiber optic laryngoscopy (FOL) is very helpful.

Objective: To identify lesions in the larynx in patients with persistent upper airway disorders and to compare the diagnostic yield of FOL over $\mathrm{I} / \mathrm{L}$.

Method: This was a cross-sectional study conducted partly in department of ENT and Head \& neck surgery, BIRDEM General Hospital and partly at the same department of BSMMU during the period of July to December 2012. 100 adult patients were taken having upper airway symptoms. Study subjects were evaluated by history, physical examinations, and ENT examinations. All patients underwent indirect laryngoscopy and FOL. Data were recorded and analyzed.

Results: Age of the respondents was between 18-72 years. The mean $\pm S D$ was $54 \pm \mathbf{1 1 . 7 9}$ years. Common symptoms among the participants were hoarseness, sore throat, neck

\section{Introduction:}

Fiberoptic imaging was initially developed to visualize inaccessible regions of the body ${ }^{1}$. Current fiberoptic nasopharyngolaryngoscopes are lighted, are flexible with 2-way articulation, provide high resolutio photo

a. Dr. Shawhely Mahbub, Senior Medical Officer, Dept.of ENT and Head \& Neck surgery, BIRDEM General Hospital.

b. Prof. (Dr) Ali Zaheer Al-Amin, Professor \& Head, Department of Otolaryngology \& Head-Neck surgery, BIRDEM General Hospital.

c. Dr. Sudhangshu Shekhar Biswas, Assistant Professor, Dept. of ENT and Head \& neck surgery, BIRDEM General Hospital.

d. Dr. Mohammad Shah Jamal, Assistant Professor, Department of Gastroenterology, Comilla Medical College \& Hospital

Address of Correspondence: Dr. Shawhely Mahbub, Senior Medical Officer, Department of ENT and Head \& Neck Surgery, BIRDEM General Hospital, 122, Kazi Nazrul Islam Avenue, Shahbag, Dhaka, Mobile: 01715366726.

Received: 23 September, 2013 swelling, breathless ness, cough, odynophagia, earache etc. On I/L examinations $30 \%$ were vocal cord polyps, $14 \% \mathrm{v}$. cord edema, $17 \%$ v. cord growths, $11 \%$ v. cord nodules, $6 \%$ v. cord palsy, 4\% ulcerated lesions, $13 \%$ poor vision and $5 \%$ were normal. On FOL examinations, $30 \%$ were vocal cord polyp, $18 \%$ v. cord edema, $21 \%$ v. cord growth, $14 \%$ v. cord nodule, $8 \%$ v. cord palsy, 5\% ulcerated lesion, 2\% laryngeal web, $2 \%$ were normal study and there were no poor vision. A comparison was made between the findings of $\mathrm{I} / \mathrm{L}$ and FOL which showed that FOL is superior to $\mathrm{I} / \mathrm{L}$ in diagnosing upper airway disorders as evidenced by findings of $2 \%$ lesions among 5\% patients having normal I/L findings. Chi-square test was done between $\mathrm{I} / \mathrm{L}$ and $\mathrm{FOL}$ findings which was statistically significant; (P value was .002) i.e. FOL procedure is valuable diagnostically in comparison to $\mathrm{I} / \mathrm{L}$.

Conclusion: In many occasions I/L findings are inconclusive in daily ENT practice. Moreover, in some cases there is poor vision to identify the lesion. Therefore, Routine FOL evaluation is valuable in patients with significant, chronic and progressive upper airway symptoms. It should always be considered in patients with persisting and progressive symptoms even though $\mathrm{I} / \mathrm{L}$ appeared normal.

(J Banagladesh Coll Phys Surg 2014; 32: 200-205)

and video capabilities, and can have a distal diameter as small as $2 \mathrm{~mm}^{2}$.

Fiberoptic nasopharyngolaryngoscopy can allow visualization of the following structures ${ }^{3}$ : nasal cavity, septum, middle meatal space and infundibulum, frontal recess, sphenoid, ethmoid recess, turbinates, posterior choanae, eustachian tube orifices, adenoid if any, nasopharynx, posterior surface of the uvula and palate, velopharyngeal valve, base of the tongue, pharyngeal and lingual tonsils, vallecula, part of pyriform spaces, epiglottis/ supraglottis, glottis and immediate subglottis with mobility or immobility of the vocal folds and arytenoids ${ }^{4,5}$.

Fiberoptic nasopharyngolaryngoscopy is indicated when visualization of the nasopharyngolaryngeal anatomy is needed for diagnosis, treatment, or both ${ }^{6}$. In the nasal cavity, fiberoptic nasopharyngolaryngoscopy can 
visualize polyps, tumors, foreign bodies, or sources of epistaxis. In the nasopharynx, the scope can help identify suspected tumors or adenoidal hypertrophy ${ }^{7}$. In the oropharynx or hypopharynx, fiberoptic nasopharyngolaryngoscope may be used to evaluate foreign bodies and potential airway obstruction from such etiologies as neoplasm and also other pathologies like tonsillar hypertrophy, glossoptosis, or laryngomalacia ${ }^{8}$. In the vocal cords- polyps, nodules, SOL, and paralysis of its movement can also be identified with fiberoptic laryngoscopy ${ }^{9}$.

Another application for nasopharyngolaryngoscopy is assessment of velopharyngeal insufficiency ${ }^{10}$. While the patient counts aloud or repeats a specific phrase, the nasopharyngolaryngoscope in the nasopharynx can be used to assess the pattern of velopharyngeal closure ${ }^{11}$. Fiberoptic endoscopic evaluation of swallowing (FEES) has emerged as a comparable alternative to video fluoroscopy and modified barium swallow in the evaluation of dysphagia and aspiration during swallowing ${ }^{12}$. Nasopharyngolaryngoscopy is considered a benign procedure with few contraindications and mild complications in experienced hands ${ }^{13}$.

Upper airway disorders are very common. These are frequently encountered in daily ENT practices. These patients are commonly treated with antihistamines and antibiotics without proper evaluation of the upper airway. Although many patients are examined with indirect laryngoscopy, this is not always conclusive and visualization is poor ${ }^{14}$. Fiberoptic laryngoscopy is the procedure by which upper airway can be examined appropriately with adequate illumination and visualization. Findings can also be displayed for all with monitor. Therapeutic procedures can be done as well in selected cases ${ }^{15}$.

In this study an attempt had been made to find out the laryngeal lesions in symptomatic patients with the help of FOL and to compare the diagnostic yields of FOL with that of I/L

\section{Methods:}

This was a cross-sectional analytic study conducted with 100 adult patients having upper airway symptoms to evaluate their airway and their socio-demographic characteristics and attributes associated with the symptoms. All study subjects were underwent indirect laryngoscopy (I/L) and Fiberoptic laryngoscopy (FOL) procedures (Pentax, G112031 Japan, FNL10RBS was used in BIRDEM \& Model-FNL-15RP3, Sl \# A110462, Pentax, Japan was used in BSMMU). The total period of study was from July 2012 to December 2012. The study was undertaken partly at the department of otolaryngology \& Head-Neck Surgery, BIRDEM and at partly at the department of otolaryngology \& HeadNeck Surgery, Bangabandhu Sheikh Mujib Medical University (BSMMU). Eligible subjects with persistent upper airway symptoms for more than three weeks who does not improved with conservative measures were included- Patients seen at ENT outpatient department (OPD) of BIRDEM \& BSMMU, In patients of ENT department of BIRDEM \& BSMMU, referred patients from different departments like Internal medicine, Endocrinology, Nephrology, Surgery and other departments of BIRDEM hospital - enrolled after informed consent. After ethical clearance, data were collected by face to face interview using a semistructured questionnaire and from procedures results review. Data were analyzed by SPSS software, cross tabulation, chi square test and independent sample tests.

\section{Results:}

In this study the respondents aged $18-72$ years were selected. The mean \pm SD of age of the respondents was $54 \pm 11.79$ years and $33.8 \%$ respondents were of 55 to 64 age group. Maximum and minimum age was 72 and 18 years where range was 53 years (Table- I).

\section{Table-I}

\section{Age group distributions among the patients}

\begin{tabular}{lcc}
$\begin{array}{l}\text { Age group } \\
\text { (in Years) }\end{array}$ & Frequency (n) & Percent (\%) \\
\hline $18-28$ & 17 & 17 \\
$29-38$ & 14 & 14 \\
$39-48$ & 12 & 12 \\
$49-58$ & 22 & 22 \\
$59-68$ & 16 & 16 \\
$69-72$ & 19 & 19 \\
\hline Total & 100 & 100 \\
\hline
\end{tabular}

Almost three-fourth were male and one-fourth was female. Female patients were 22 (22.0\%) and rests were male 78 (78.0\%). Data was mostly collected at working hours which might be the reason for presence of high proportion of male in the sample unit. Regarding 
educational status $65 \%$ were up to SSC, $18 \%$ HSC, $8 \%$ graduate and $9 \%$ were illiterate. On occupation, $62 \%$ were businessman, 22\% were service holders, $14 \%$ housewives, and $2 \%$ were jobless. Common symptoms among the participants were hoarseness of voice, sore throat, neck swelling, breathless ness, cough, odynophagia, earache etc (Table- II).

\section{Table-II}

\begin{tabular}{lcc}
\multicolumn{3}{c}{ Symptoms among the patients $(n=100)$} \\
Symptoms & Frequency (n) & Percent (\%) \\
\hline Hoarseness of voice & 57 & 57 \\
Breathlessness/stridor & 5 & 5 \\
Sore throat & 4 & 4 \\
Neck swelling & 2 & 2 \\
Difficulty in swallowing & 13 & 13 \\
Other (cough) & 19 & 19 \\
\hline Total & 100 & 100 \\
\hline
\end{tabular}

On indirect laryngoscopic ( $\mathrm{I} / \mathrm{L}$ ) examinations $30 \%$ were vocal cord polyp, $14 \% \mathrm{v}$. cord edema, $17 \%$ v. cord growth, $11 \% \mathrm{v}$. cord nodule, $6 \% \mathrm{v}$. cord palsy, $4 \%$ ulcerated lesion, $13 \%$ poor vision and $5 \%$ were normal study(Figure-1).

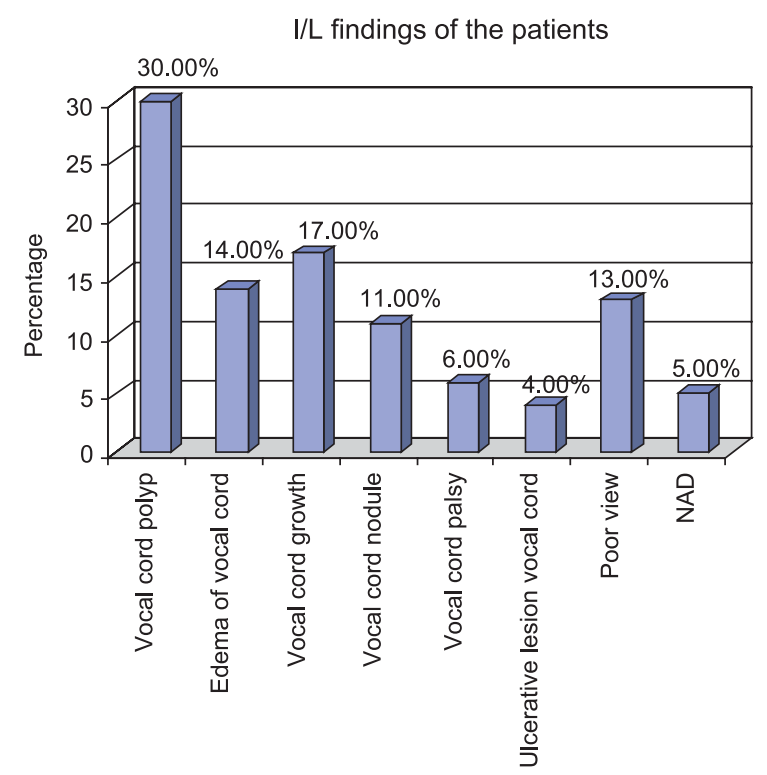

Fig.-1: I/L findings of the patients $(n=100)$
On direct laryngoscopy ( FOL) examinations, 30\% were vocal cord polyp, $18 \%$ v. cord edema, $21 \%$ v. cord growth, $14 \% \mathrm{v}$. cord nodule, $8 \% \mathrm{v}$. cord palsy, 5\% ulcerated lesion, 2\% laryngeal web, $2 \%$ were normal study and there were no poor vision(Figure-2).

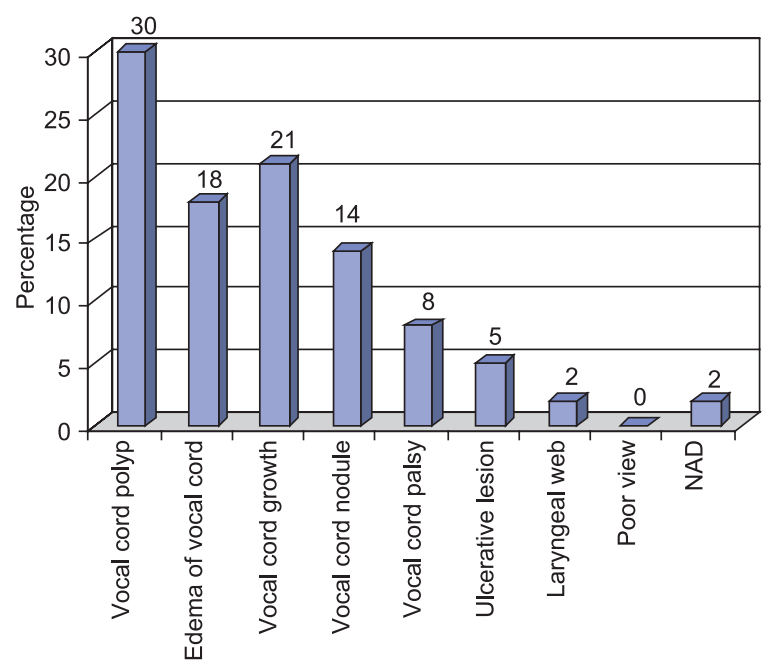

Fig.-2: FOL findings of the patients $(n=100)$

A comparison has also been made between findings of $\mathrm{I} / \mathrm{L}$ and FOL in tabulated form to see the difference at a glance (Table-III).

Finally chi-square test was done between I/L and FOL findings which was statistically significant (Table- IV).

\section{Table-III}

Comparison between findings of IL and FOL $(n=100)$

\begin{tabular}{lccccc}
\multirow{2}{*}{ Findings } & \multicolumn{2}{c}{$\mathrm{I} / \mathrm{L}$} & & \multicolumn{2}{c}{ FOL } \\
\cline { 2 - 3 } \cline { 5 - 6 } & $\mathrm{n}$ & $\%$ & & $\mathrm{n}$ & $\%$ \\
\hline V.cord polyp & 30 & 30 & & 30 & 30 \\
oedema of v. cord & 14 & 14 & & 18 & 18 \\
V. cord growth & 17 & 17 & 21 & 21 \\
V. cord nodule & 11 & 11 & 14 & 14 \\
V. cord palsy & 6 & 6 & 8 & 8 \\
Ulcerative lesion & 4 & 4 & 5 & 5 \\
Laryngeal web & 0 & 0 & 2 & 2 \\
Poor view & 13 & 13 & & 0 \\
NAD & 5 & 5 & & 2 \\
\hline Total & 100 & 100 & 100 & 100 \\
\hline
\end{tabular}


Table-IV

Chi-Square test of I/L and FOL findings ( $n=100)$

\begin{tabular}{lcccccc} 
Procedure & lesion & no lesion & total & $X^{2}$ & df & p value \\
\hline I/L & 82(82.0\%) & 18(18.0\%) & $100(100.0 \%)$ & & & \\
FOL & $98(98.0 \%)$ & 02(2.0\%) & $100(100.0 \%)$ & & & 0.002 \\
\hline
\end{tabular}

Note: On I/L examination lesion found in $82.0 \%$ cases. On the other hand On FOL examination lesion was found in $98.0 \%$ cases. Statistically these differences were found significant.

\section{Discussion:}

Upper airway disorders are the common ENT disorders encountered in general practice. Malignancy is an important cause of upper airway symptom ${ }^{16}$. However, other common causes of these symptoms are v. cord nodule, v. cord polyp, v. cord edema, chronic laryngitis etc. In some instances, over use of voice or voice abuse contribute to the development of these symptoms. The consumption of tobacco, alcohol, betel leaf, drugs etc can also lead to development of these symptoms in the absence of significant pathology ${ }^{17}$.

Upper air way lesions may remain silent initially; may be evident only when the patient is symptomatic. Studies regarding endoscopic evaluation of upper airway diseases are few. Therefore it is difficult to conclude which factors predict the laryngoscopic outcome in upper airway symptomatic patients.

A prospective study-"Benign vocal cord lesions - a study of 25 cases" was carried out in the department of Otolaryngology and Head-Neck Surgery of Sir Salimullah Medical College \& Mitford Hospital, Dhaka $^{18}$. The study revealed- Vocal cord polyp12(48\%), Vocal cord nodule- 05 (20\%), Vocal cord papilloma-1(04\%) and Multiple papillomatoseses $07(28 \%)^{18}$.

In one study- a comparative study among direct, indirect and fiber optic laryngoscopy to evaluate v. cord paralysis after thyroid surgery revealed that FOL is the best method for evaluating the upper airway disorders ${ }^{19}$.

In our study the respondents aged 18-72 years were selected. The mean \pm SD of age of the respondents was $54 \pm 11.79$ years. Among the study subjects majority were in 49 to 58 years age group (22.0\%) followed by 69 years \& above age group (19.0\%).
So majority being within 49 to 58 years age group suggests a more occurrence of upper airway lesions in this age group. But there may be other factors underlying this as well.

About three-fourth were male and one-fourth was female. Female 22(22.0 \%) and rests were male 78 (78.0 $\%)$. This also indicates an increased occurrence of upper air way diseases in male than female. Smoking and exposure to other noxious agents, overuse of voice etc. are more common in male which might be predisposing factors for male preponderance. Moreover, data was mostly collected at working hours which might also be a reason for presence of high proportion of male in the sample unit.

Regarding educational status $65 \%$ were at and below SSC, $18 \%$ HSC, $8 \%$ graduate and $9 \%$ were illiterate. It has been seen that, the more educated patients are more health conscious \& presents early, thus disease is detected at an early stage. Many cancer patients can be treated with a curative intend if they presents at an early stage of the disease.

Common symptoms among the participants were hoarseness, sore throat, neck swelling, breathless ness, cough, odynophagia, earache etc. Majority patients were presented with hoarseness (57\%), among them majority patients were diagnosed as benign disease, i.e. vocal cord polyp, nodule \& edema.

On occupation, $62 \%$ were businessman, $22 \%$ were service holders, $14 \%$ housewives, and $2 \%$ were jobless. Vocal cord nodule was seen more in patients who were housewife \& had small children. Among the service holders, patients who are teachers of primary school had presented with vocal cord edema- may be due to over use of voice. Another thing is that, majority of the study population are businessman in occupation. So 
there may be some occupational exposure relating to the disease occurrences.

On indirect laryngoscopic ( $\mathrm{I} / \mathrm{L}$ ) examinations $30 \%$ were vocal cord polyp, $14 \%$ v. cord edema, $17 \%$ v. cord growth, $11 \% \mathrm{v}$. cord nodule, $6 \% \mathrm{v}$. cord palsy, $4 \%$ ulcerated lesion, $13 \%$ poor vision and $5 \%$ were normal study.

On direct laryngoscopy ( FOL) examinations, 30\% were vocal cord polyp, $18 \%$ v. cord edema, $21 \%$ v. cord growth, $14 \% \mathrm{v}$. cord nodule, $8 \% \mathrm{v}$. cord palsy, 5\% ulcerated lesion, $2 \%$ laryngeal web, $2 \%$ were normal study and there were no poor vision. This $2 \%$ symptomatic patients having normal upper airway on laryngoscopic examination may be due to an allergic, functional or a lower respiratory disorders.

A comparison has also been done between findings of $\mathrm{I} / \mathrm{L}$ and FOL in tabulated form to see the difference at a glance. This showed that fiber optic laryngoscopic examination is superior to indirect laryngoscopy in diagnosing upper airway disorders which is evidenced by findings of $2 \%$ lesions among $5 \%$ patients having normal I/L findings.

Finally chi-square test was done between I/L and FOL findings which was statistically significant; ( $P$ value was .002) i.e. this study revealed that FOL procedure is valuable diagnostically in comparison to I/L.

Although optimum care had been tried in every steps of this study, still some limitations existed:

The study was conducted in a selected institution. So the study population might not represent the whole community. Probability sampling technique could not be employed to recruit the study unit; they were selected purposively due to time constraints. As a result, there might be some selection bias. In spite of maximum effort by the researcher due to time and resource limitation sample size was small; a larger sample size would have given a better result.

\section{Conclusion:}

In this study, an evaluation was made over the study population having upper airway symptoms. The evaluation was done with I/L and FOL procedures over the study population. A comparison was also made between the findings of I/L and FOL. The aim was to see the diagnostic yield of FOL over I/L. In our study, majority of the study population had lesions on $\mathrm{I} / \mathrm{L}$.
Some participants had poor vision and some had normal upper airway on I/L. Study showed that many of the study subjects having poor vision and normal I/L findings had lesions on FOL. Some new lesions (e.g. web) were also detected on FOL which were not detectable on I/L. Moreover, significant lesions (e.g. malignancy) were detected on FOL than I/L. Therefore, Routine FOL evaluation is valuable in patients with significant, chronic and progressive upper airway symptoms. It should always be considered in patients with persisting and progressive symptoms even though $\mathrm{I} / \mathrm{L}$ appeared normal. Further research is expected to shed light on the role of FOL, in particular to investigate whether this modality improves outcomes.

\section{Recommendation}

- Every chronic, progressive or persistent upper airway symptoms should be evaluated carefully with FOL when I/L finding is inconclusive or even normal.

- Primary care physicians should be informed that only drug treatment or I/L examination is not sufficient for persistent or progressive upper airway symptoms; rather the patient should be referred for FOL.

- Further in depth research should be conducted to clarify the importance of FOL in patients with upper airway disorders.

\section{References:}

1. Elluru R, Willging P. Endoscopy of the pharynx and esophagus. In: Cummings C, ed-in-chief. Otolaryngology: Head \& Neck Surgery. $4^{\text {th }}$ ed. Philadelphia, Pa: Mosby, Inc; 2005:79.

2. Caylakli F, Hizal E, Yilmaz I, Yilmazer C. Correlation between adenoid-nasopharynx ratio and endoscopic examination of adenoid hypertrophy: a blind, prospective clinical study. Int J Pediatr Otorhinolaryngol. 2009 Nov; 73(11):1532-5. Epub 2009 Sep 3.

3. Welch K, Goldberg A. Sleep disorders. In: Lalwani A. Current Diagnosis \& Treatment in Otolaryngology-Head \& Neck Surgery. McGraw-Hill Companies, Inc; 2004:39.

4. Cantrell RW, Bell RA, Morioka WT. Acute epiglottitis: intubation versus tracheostomy. Laryngoscope. Jun 1978;88(6):994-1005.

5. Arndal H, Andreassen UK. Acute epiglottis in children and adults. Nasotracheal intubation, tracheostomy or careful observation? Current status in Scandinavia. J Laryngol Otol. Nov 1988;102(11):1012-6.

6. Tan AK, Manoukian JJ. Hospitalized croup (bacterial and viral): the role of rigid endoscopy. J Otolaryngol. Feb 1992;21(1):48-53. 
7. Patton DD. Office procedures. Nasopharyngoscopy. Prim Care. Jun 1997;24(2):359-74.

8. Ngan JH, Fok PJ, Lai EC, et al. A prospective study on fish bone ingestion. Experience of 358 patients. Ann Surg. Apr 1990;211(4):459-62.

9. Choy AT, Gluckman PG, Tong MC, et al. Flexible nasopharyngoscopy for fish bone removal from the pharynx. J Laryngol Otol. Aug 1992;106(8):709-11.

10. Faber CE, Grymer L. Available techniques for objective assessment of upper airway narrowing in snoring and sleep apnea. Sleep Breath. Jun 2003;7(2):77-86.

11. Svensson M, Holmstrom M, Broman JE, et al. Can anatomical and functional features in the upper airways predict sleep apnea? A population-based study in females. Acta Otolaryngol. Jun 2006;126(6):613-20.

12. Dudas JR, Deleyiannis FW, Ford MD, et al. Diagnosis and treatment of velopharyngeal insufficiency: clinical utility of speech evaluation and videofluoroscopy. Ann Plast Surg. May 2006;56(5):511-7; discussion 517.
13. Langmore SE. Evaluation of oropharyngeal dysphagia: which diagnostic tool is superior?. Curr Opin Otolaryngol Head Neck Surg. Dec 2003;11(6):485-9.

14. Wrigley SR, Black AE, Sidhu VS. A fibreoptic laryngoscope for paediatric anaesthesia. A study to evaluate the use of the $2.2 \mathrm{~mm}$ Olympus (LF-P) intubating fibrescope. Anaesthesia. Aug 1995;50(8):709-12. [Medline].

15. Alalami AA, Ayoub CM, Baraka AS. Laryngospasm: review of different prevention and treatment modalities. Paediatr Anaesth. Apr 2008;18(4):281-8. [Medline].

16. Wai Pak M, Chung Lee W, Kwok Fung H, et al. A prospective study of foreign-body ingestion in 311 children. Int J Pediatr Otorhinolaryngol. Apr 6 2001;58(1):37-45. [Medline].

17. Report of Rhinosinusitis Tank Force Committee meeting Otolaryngology and head \& neck surgery 1997; 117: S1-68.

18. Abdullah M. Endoscopic Sinus Surgery-Recent Advancement in Oto-Rhino-Laryngological Practice. Sir Slimullah Medical College Journal 2005; 13: 52-54

19. Koltai PJ, Nixon RE (1989). "The story of the laryngoscope”. Ear, Nose, \& Throat Journal 68 (7): 494-502. PMID 2676465 